\title{
Software Junctus: Joining Sign Language and Alphabetical Writing
}

\author{
Carla Beatris Valentini, Cláudia A. Bisol, and Cristiane Dalla Santa \\ Universidade de Caxias do Sul, Rua Francisco Getúlio Vargas, 1130 \\ 95070 Caxias do Sul, Brazil \\ cbvalent@ucs.br, cabisol@ucs.br, crisdallas@gmail.com
}

\begin{abstract}
The authors' aim is to describe the workshops developed to test the use of an authorship program that allows the simultaneous use of sign language and alphabetical writing. The workshops were prepared and conducted by a Computer Science undergraduate, with the support of the Program of Students' Integration and Mediation (Programa de Integração e Mediação do Acadêmico - PIMA) at the University of Caxias do Sul. Two sign language interpreters, two deaf students and one hearing student, who also teach at a special school for the deaf, participated in the workshops. The main characteristics of the software and the development of the workshops are presented with examples of educational projects created during their development. Possible improvements are also outlined.
\end{abstract}

Keywords: Computerized learning environment, authorship software, deafness, sign language, alphabetical writing.

\section{Introduction}

Sign languages are natural and complex languages shared by individuals who identify themselves as deaf. These individuals belong to a community, a linguistic and cultural minority with distinctive mores, attitudes and values [1]. In each country the deaf community developed their own language. In Brazil, Brazilian Sign Language (Libras) was recognized as an official language in 2002, and bilingual education has been the approach chosen by a large number of special schools for the deaf since it was introduced in the country in the 1990s [2]. This approach is based on the understanding that the deaf children's cognitive and linguistic development will be facilitated when sign language is used to create a natural and rich context of communication. The oral language of the country is then introduced to the deaf child as a second language for the development of reading and writing skills [3] and [4].

The ability to make use of the dominant language of a country in its written form broadens the horizon of deaf individuals, allowing them more access to the information that circulates in society through different media and increasing their chances for better educational and job opportunities. However, reading and writing is difficult for deaf pupils. Researchers have well established this fact and teachers know it from their daily experience [5]. Deaf children lack access to spoken language so they are 
not able to use efficiently sounding out processes that help them to learn how to read [6]. Also, the form and structure of the signed language that they use is not related to the spoken or written form of oral language.

Considering that digital technology can increase capacity for communication and learning, new strategies can be created to improve the education of deaf children. With the objective of allowing the simultaneous use of sign language and alphabetical writing, the authorship program Junctus was developed [7]. This article describes workshops developed in the year of 2008 to test the use of this software. The workshops were organized and conducted by an undergraduate Computing trainee at the facilities of the Program of Students' Integration and Mediation (Programa de Integração e Mediação do Acadêmico - PIMA ${ }^{1}$ ) at the University of Caxias do Sul. Two sign language interpreters, two deaf students and one hearing student who also teaches at a special school for the deaf participated in the workshops. After a short introduction describing the main characteristics of the software, this article discusses how the workshops were developed, presents examples of educational projects created during these activities, and outlines possible improvements.

\section{The Autorship Program Junctus}

The learning environment Junctus was developed using Java platform, created by Sun Microsystems [8], which is available as an open-source system. One principle that guided the development of this framework was the need of guaranteeing adequate usability. Therefore, all efforts were made to create an interface that should be simple to use and, at the same time, should offer the functionalities proposed to allow the integration of different forms of representation.

In the development of this framework, the main functionalities were encapsulated in modules (classes) as independent as possible, so each module is responsible for one form of representation. In the current prototype these forms are video and text. As the rest of the framework is independent of the implementations of the other modules, it is possible to extend the system to incorporate other forms of representation.

Videos are captured from several forms of digital recordings. The framework allows the integration of video and text, so the simultaneous use of video-recorded narratives in sign language and the corresponding written text is possible. To establish the links between video and text, the user selects in the video the segments corresponding to the segment selected in the text, "editing" the project. Each project developed by a user-apprentice corresponds to the construction of this relation between text and video. Therefore, it is possible to construct representations in a visuo-space language (sign language) and alphabetical writing simultaneously.

Junctus presents several functionalities that can be adapted to the user's needs. The Menu Bar shows the following options: File (to create new files, open existing files, save and exit), Edit (including a creation option that makes available a specific window to link video and text) and Help (general information about Junctus).

\subsection{Creation Mode}

Figure 1 presents the interface of the environment when beginning a new project. This interface presents the following windows: Creation, Video, Text, and List of Links. Next, the functions of these windows will be briefly described. 


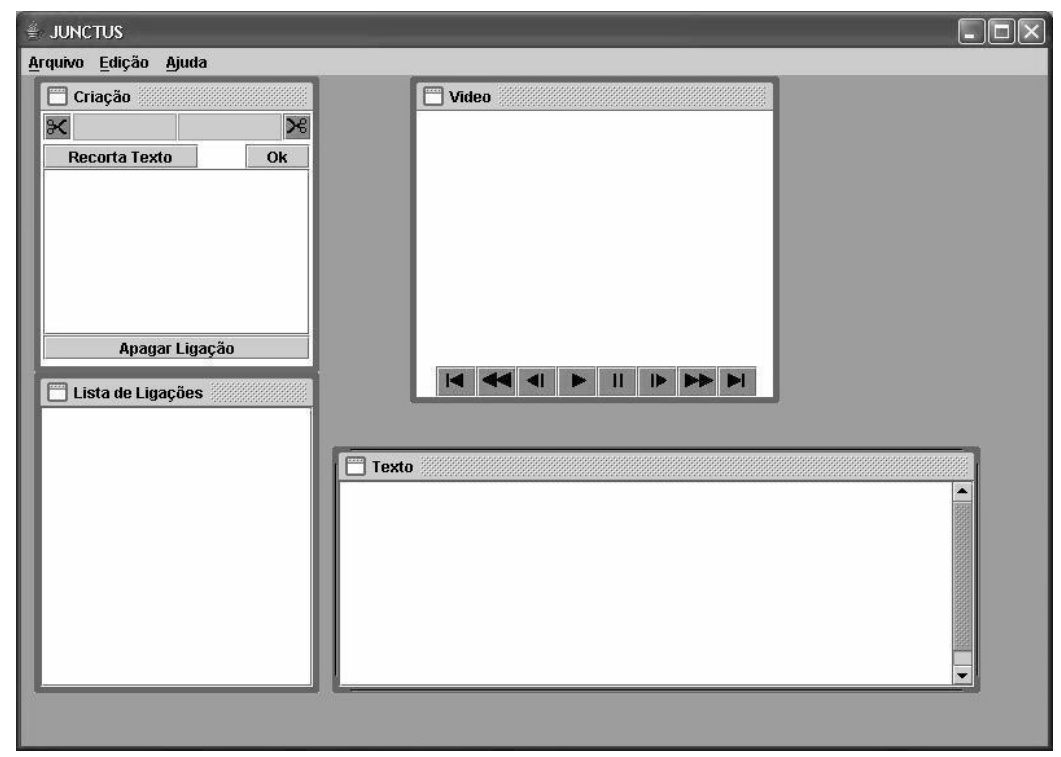

Fig. 1. Interface of the environment Junctus

The Text window can be used for the editing of a new document and/or addition of a document that already exists. Video handling is executed with the tools located in the Video window. After positioning the video in the desired frame, the cutting tools that appear in the Creation window can be used. With these tools it is it is possible to capture the beginning and the end of the video segment that one wishes to link to a part of the text. Once the text and the video segments are defined, clicking the OK button will confirm the creation of a new link between the two forms of representation.

\subsection{Visualization Tools}

Clicking one of the items presented in the List of Links window allows the visualization of the text associated to the link. A double click on a text segment in the List of Links window will begin the corresponding video segment and the text segment will be marked, as shown in Figure 2:

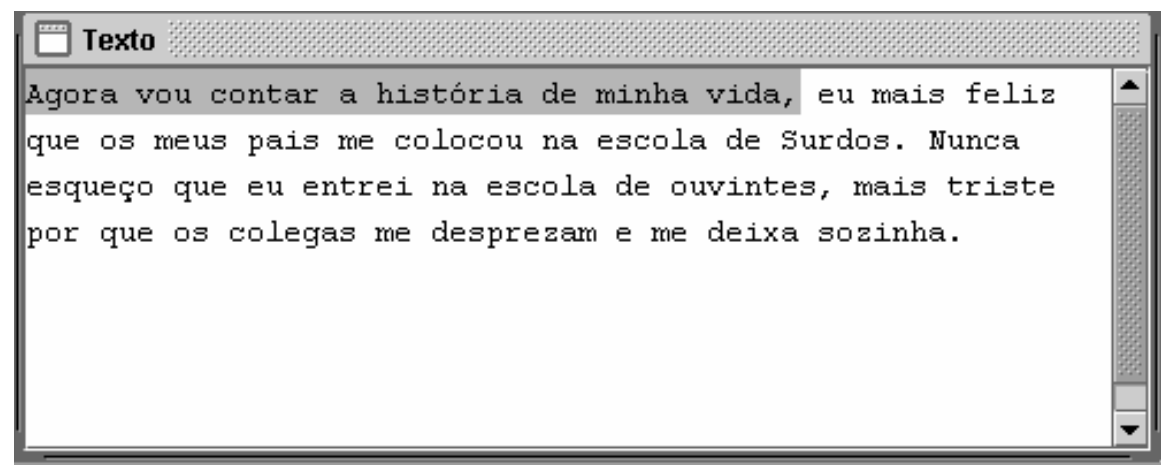

Fig. 2. Visualization of text linked to the video segment 


\section{Learning Scenario: Testing the Use of the Software}

The application scenario of the authorship program Junctus that was analyzed in this article is related to the possibilities of using this computerized learning environment in educational projects to support the inclusion of deaf students in higher education. The objective of this proposal was to offer deaf students who are regularly enrolled in undergraduate courses of the University of Caxias do Sul and sign language interpreters the opportunity to learn how to use the software, knowing and applying its functionalities in an independent way. Also, they were given the opportunity to evaluate the software and its use and suggest modifications or inclusion of new functionalities.

In order to develop this proposal, the research group relied on the participation of an undergraduate Computing trainee. She developed the workshops and prepared a manual focusing on the needs of this clientele. Her work was oriented by the researchers who author this article and by the trainee's academic supervisor. The work proposal was organized to be developed in three workshops of five meetings each. The activities took place in a special room at PIMA, equipped with computers and webcams that are available to be used by the deaf students and the sign language interpreters. The workshops were organized in such a way as to consider four stages for learning the abilities necessary for the appropriation of the software by the users, and for the development of a project using the environment offered by Junctus.

First, an overview of the workshop was presented in power point slides. Also in this first stage, the focus was on the abilities necessary for installing the program, understanding the functionalities of the software and capturing and storing videos. Through dialogued exposition, a general view of the program was presented, detailing the form of installation, the procedures for video recording and for management of archives and folders. Each subject presented were followed by guided practical activities. The general view of the program allowed participants to anticipate possibilities for developing educational projects that could answer some of their needs.

In the second stage the work focused on text, video and project differentiation, open and save commands, understanding the functionality "creation" and how to start making links. Activities were conducted so that participants could use and experiment with the software. They received a printed manual that guided their progress step by step, and could take individual notes to facilitate understanding of the procedures. Three tasks were then developed: the first was to insert text; the second was to create links between video and text; the third was to recognize the extension of the archives that were generated and present an idea for a practical use of the software.

In the third stage, the contents presented so far were reviewed and the levels of understanding were evaluated. Also, participants were asked to start to develop their own educational projects involving sign language.

It is important to emphasize that the growing access that deaf people have in higher education has led to the need to develop new signs in Brazilian Sign Language (Libras) related to each specific area of knowledge. The deaf community has been using different strategies to transmit to one another the new vocabulary they create. Among these strategies one can find the use of Libras-Portuguese dictionaries available on the internet, the use of drawings to represent the signs, and their full description in Portuguese. However, the full description of signs in Portuguese or their drawing is not very simple and might present certain difficulties for representation and interpretation, because sign languages are gestural and visual languages; therefore they make use of three-dimensional space. 
Understanding how the software functioned and the possibilities it offered allowed participants to propose a small educational project to be developed during the workshops. The two sign language interpreters and the hearing student decided to use the computerized learning environment to share new technical concepts, especially because Junctus allows the explanation of technical concepts to be linked with the word or sign. The interpreters' objectives were to register these new signs and make them available to other interpreters and deaf students so communication in the classroom could be further enhanced. One of the screens of one of the projects developed by the interpreters can be seen in the figure below.

While working with the deaf students to decide which educational project they would develop, students also came up with the idea of using Junctus as a way to transmit technical concepts and the disciplines' contents of each course and to share specific signs usually used during classes. For the project to be developed during the workshop, they chose some of the disciplines they successfully attended. For instance, they chose the basic course in Embryology and summarized its objectives, the kind of content that was developed, and the difficulties that are usually faced by students in this course.

The forth and last stage of the workshop aimed at finishing the projects initiated in stage three and conducting an evaluation of the software and of the workshops as a whole. All the educational projects were finished successfully. The workshops were evaluated positively: the didactic techniques used by the trainee was considered good and respectful of the linguistic differences when working with the deaf students; the organization of the workshop in four stages helped participants to clearly identify the objectives of each meeting and what was expected of the participants to do; participants found the printed manual helpful and easy to understand. Suggestions regarding the improvement of the software as well as critiques are discussed in the conclusion session.

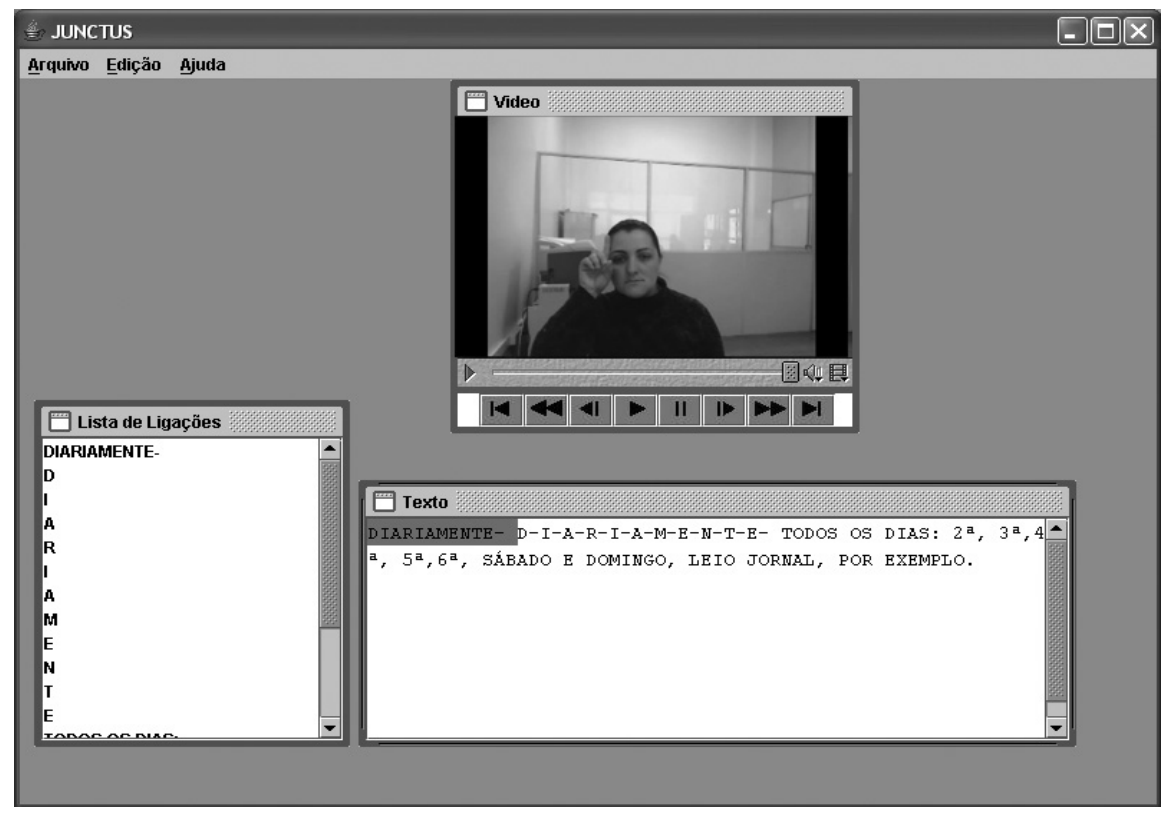

Fig. 3. Sign language interpreter's project about new signs 


\section{Conclusion}

For a computerized learning environment to be successful, it has to be used and tested in real-life situations. The workshops that were presented in this article provided the chance to test the authorship program Junctus in a university setting, with the help of a Computing trainee and with the participation of hearing and deaf students and sign language interpreters. Validation includes evaluation of functionality, usability, performance, and pedagogical potential. This process can lead to a proposal for an improved version of the software.

Suggestions in terms of functionality included: a) create the possibility to save videos within the software; b) add an orthographic corrector and c) use different kinds of video files and not VCD exclusively. Usability could be enhanced if: a) different colors could be chosen for each link; b) the video window could be resized according to the users' preferences; c) the way files are saved and opened could be improved; and d) selection of videos could be more precise. Also, improving the visualization of the links (text and video) when the user searches for a single sign or phrase can optimize the performance of the software.

Several aspects can be thought of when considering the pedagogical potential of Junctus. As an authorship software, it showed flexibility to adapt to different pedagogical contexts such as those required by hearing and deaf students. The software can be used by the students to create educational projects such as those exemplified in this article, but it could also be used by teachers to organize learning materials. Also, evaluation with deaf students is challenging both for teachers and students due to the use of sign language and the need for interpreters. With the use of this software, students could prepare their material both in sign language and alphabetical writing, allowing teachers to better understand their learning processes.

The actual use of this computerized learning environment has opened new application possibilities and future perspectives. For instance, after the use of the software in the workshops at the Program of Students' Integration and Mediation, the coordinators and interpreters decided to use it to create a database of documents and guidelines of the university. The objective of this database is to provide deaf students with an easy access to important information regarding academic life. As for future perspectives, a second version of the software is being studied. The aim is to allow users to develop their projects in collaboration, interacting via the web.

Acknowledgement. The present study was supported by the University of Caxias do Sul. We would like to extend our gratitude to Prof. Ricardo Dorneles and Prof. Jonathan Tudge for commenting on the English version.

\section{References}

1. Lane, H.: Do deaf people have a disability? In: H-Dirksen, L.B. (ed.) Open your eyes: Deaf Studies talking, pp. 277-292. University of Minnesota Press, Minneapolis (2008)

2. Meirelles, V., Spinillo, A.G.: Uma análise da coesão textual e da estrutura narrativa em textos escritos por adolescentes surdos [Textual cohesion and narrative structure in written texts produced by deaf adolescents]. Estud. psicol. (Natal) 9(1), 131-144 (2004) 
3. Capovilla, F.C., Capovilla, A.G.S.: Educação da criança surda: o bilingüismo e o desafio da descontinuidade entre a língua de sinais e a escrita alfabética [Deaf child education: bilingualism and the challenge posed by the discontinuity between sign language and alphabetic writting]. Rev. bras. educ. espec. 8(2), 127-156 (2002)

4. Lacerda, C.B.F.: Um pouco da história das diferentes abordagens na educação dos surdos. [A short history of different approaches to the education of the deaf]. Cad. CEDES 19(46), 68-80 (1998)

5. Watson, L.M.: Literacy and deafness: the challenge continues. Deafness Educ. Int. 1(2), 96107 (1999)

6. Padden, C., Ramsey, C.: American Sign Language and Reading Ability in Deaf Children. In: Chamberlaine, C., Morford, J.P., Mayberry, R.I. (eds.) Language Acquisition by Eye, pp. 165-190. Lawrence Erlbaum Associates, Mahwah (2000)

7. Valentini, C.B., Bisol, C.A., Casa, M.E., Sgorla, E.: Um software de autoria para a educação de surdos: integração da língua de sinais e da língua escrita [An autorship software for the education of the deaf: Integration of sign language and written language]. Revi. CINTED-UFRGS 4(2), 2-10 (2006)

8. Java, Java Technology (2005), http: / / java. sun. com 